\title{
Spatial Distribution and Changing Scenario of Green Space using Geospatial Techniques in Jangalmahal Area, Paschim Medinipur and Jhargram District,West Bengal, India
}

\author{
Subrata Sarkar ${ }^{1}$, Nirupam Acharyya ${ }^{2}$, Jatisankar Bandyopadhyay ${ }^{3}$ \\ Department of Remote Sensing and GIS, Vidyasagar University, Midnapore-721102, West Bengal \\ *Corresponding Author E-mail: subratars.gis@gmail.com
}

\begin{abstract}
Application of remote sensing and GIS as tools has assumed immense significance in assessment of this information. These applications are now widely used in conservation and management of protected areas across the globe. The present study focuses on the role of Remote Sensing and Geographic Information System (GIS) in assessment of changes in forest cover, between 1990 and 2017 in Jangalmahal area Paschim Medinipur and Jhargram, West Bengal, India. The satellite imagery was used to generate spatial data of forest density of this protected area. Remote Sensing and GIS consider follows the four aspect of detecting forest changes A) Detect the changes, B) Identify the nature of changes, C) Measure the aerial extent of changes and D) Assess the spatial pattern of changes. The final results of the analysis showed that from 1990 to 2017 within a period of 27 years the forest covers has decreased by $81.37 \mathrm{sq} \mathrm{km}$. This difference was measured by using the NDVI model. After the overlay analysis the area shows that forest had been highly depleted over the past 27 years. These changes were as a result of an increase in human activities and population explosion within the study area.
\end{abstract}

Keywords- RS and GIS, Satellite Image, NDVI, Forest change detection.

\section{INTRODUCTION}

Forests and biodiversity is the very important key of all living phenomena. The good quality of forest is the batter opportunity for socio-economic development and adjusting response to the challenge of climate change persuaded disasters [9]. Geographical Information System (GIS) and Remote Sensing are the well Establishment technologies, which applications in land and water resource management are widely recognized. Generally we say that forest it the green blankets on the environment which is conserving the natural resources and naturally protecting and balancing the environment [5]. In Our country the total geographical area of forest is covered by $67.83 \mathrm{~m}$.ha. Which is $19.39 \%$ including dense forest, open forest, as well as mangroves forest [1]. Forests are the vast social and biological units of living communities. The forests communities are play a vital role for balancing and maintaining the eco-system all over the world. The measure of change detection data modelling is well defined and the thematic changing information can be guidance to more tangible insights into the underlying process involving land cover and land use changes than the information obtained from continuous changes. The change detection modelling is the process which helps to determine the changing associate with land use and land cover properties with reference to the geo-spatial multiresolution optical remote sensing data. It is help to identify the changing between the two periods or more than two periods those are uncharacteristic variation. The application of changes detection techniques are use the various field such as land use and land cover changes, forest cover changes, coastal changes, habitat fragmentation, urban sprawl and other geomorphological changes through the spatial and temporal analysis techniques such as GIS (Geographic Information System) and Remote Sensing along with digital image processing techniques. India has been well-endowed with a huge variety of forest resources. However the population pressure are continuing exploding and the subsequent growing to needs of food, fodder, small timber, fuel wood, industries etc., depletion and degradation of forests and subsequent adverse changes in ecosystem are taking place [3]. Remote sensing imagery is a precious tool for rapid mapping applications. The very high resolution remote sensing data are helps to analyzing the rate of changes as well as the casual factors of changes between the different time interval periods. This along with the spatial and temporal analysis technologies namely Geographic Information System (GIS) and Global Positioning System (GPS) help in maintaining up-to date land-use dynamics information for a sound planning and a cost-effective decision. GIS is the most important systematic technological introduction of numerous interdisciplinary spatial and statistical data that can be used in inventorying and analyzing of the environment, changing observation and prediction for current management plans. Remote Sensing helps to collecting data in different spatial, spectral, and temporal resolution from space borne sensors. For understanding the land ecosystem is dynamics the spatial and temporal analyzing technologies are most important and useful for generating scientifically based on statistical data [7]. Remotely sensed data are 
successfully utilization for land use and land cover change detection needs a careful selection of appropriate datasets. The present study is based on remote sensing \& GIS techniques supplemented with ground truth information from site specific interviews. Forest vegetation changes have been defined as the spatial and structural changes in the form of forest degradation and depletion, reducing the forest density and species diversity and the extension of arable land and other land use types inside the natural cover after its disturbance [8]. Most of these studies have analyzed spectral signatures or simple indices (calculated from reflectance data) such as the Normalized Difference Vegetation Index (NDVI). The main reasons for this unfortunate development include climate change, air pollution and increased human activities. There is a need to monitor and quantitatively measure the change in forest.

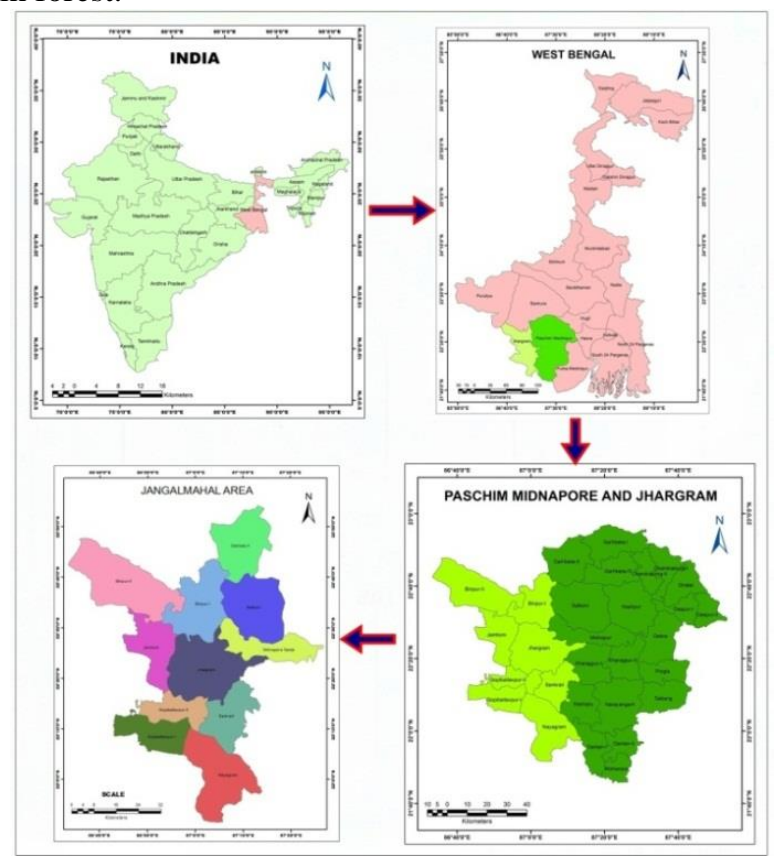

Figure 1 Location map of the study area

\section{LOCATION OF THE STUDY}

The area lies between $22^{\circ} 23^{\prime}$ to $22^{\circ} 49^{\prime}$ North Latitude and $87^{\circ} 00^{\prime}$ to $87^{\circ} 30^{\prime}$ East Longitude and the area is bounded on the north and west by Rupnarayan river and Kangshabati river. The study area is covered by two districts Paschim Medinipur and Jhargram. Three blocks are under Paschim Medinipur district i.e. Garhbeta II, Salboni and Medinipur Sadar and eight blocks are under Jhargram district i.e. Binpur-I, BinpurII, Jamboni, Jhargram, Gopiballavpur-I, GopiballavpurII, Sankrail and Nayagram. (Figure 1) The main two rivers in the study area are Subarnarekha and Kangshabati.

\section{METHODOLOGY}

The NDVI modelling was carried out to analyse the forest cover changes in the study region. The most commonly methods are used to analyze the dynamics forest cover change. It involves modelling and rectification each remotely sensed image. After the applying NDVI model, it compared the resulting maps on a pixel-by-pixel basis using a change detection matrix. The following steps were carried out in procedure of image processing: 1) data collection, 2) data preparation, 3) NDVI modelling between two periods, 4) overlay analysis and 5) preparation of change detection maps. These applications were carried out using ERDAS imagine 2014 and Arc GIS 10.3software. (Figure 2 Flow Chart of Work)

\subsection{Change Detection Methods}

The objectives of change detection are comparing of spatial representation of two time periods by control all the variance caused by differences in variables that are not of interest and the changing measurement is caused by difference in the variables of interest [2]. Many types of change detection methods are there in case of multispectral image data. They can be used NDVI modelling as two categories: characteristic analysis of spectral type, raster analysis of spectral changes and time series analysis. The aim of characteristic analysis of spectral type method is to make sure the distribution and characteristic of changes based on NDVI modelling and calculation of different phases remote sensing images. The methods are multi-temporal images stacking, algebraic change techniques of change detection have been divided into two categories one is preclassification and another is post classification.

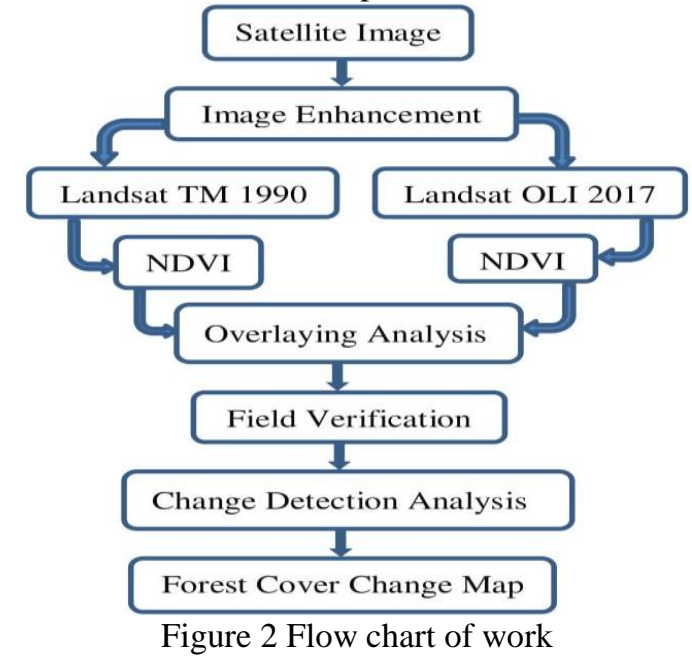

\subsubsection{NDVI}

The Normalized Difference Vegetation Index (NDVI) was introduced by in order to produce a spectral VI that separates green vegetation from its background soil brightness using Landsat TM digital image data [6]. It is expressed as the difference between the near infrared and red bands normalized by the sum of those bands. The expression of NDVI Index is as follows (NIR-RED) / (NIR+RED). (Figure $3 \& 4$ )

Healthy vegetation or the leaf area absorb the most portion of visible light and reflects the high amount of near infrared portion. The unhealthy tree leafs reflect less amount of near infrared light. The threshold values or measurement scale of NDVI ranging between -1 to +1 and if the low reflectance or low values comes in the red channel and the high reflectance comes in NIR 


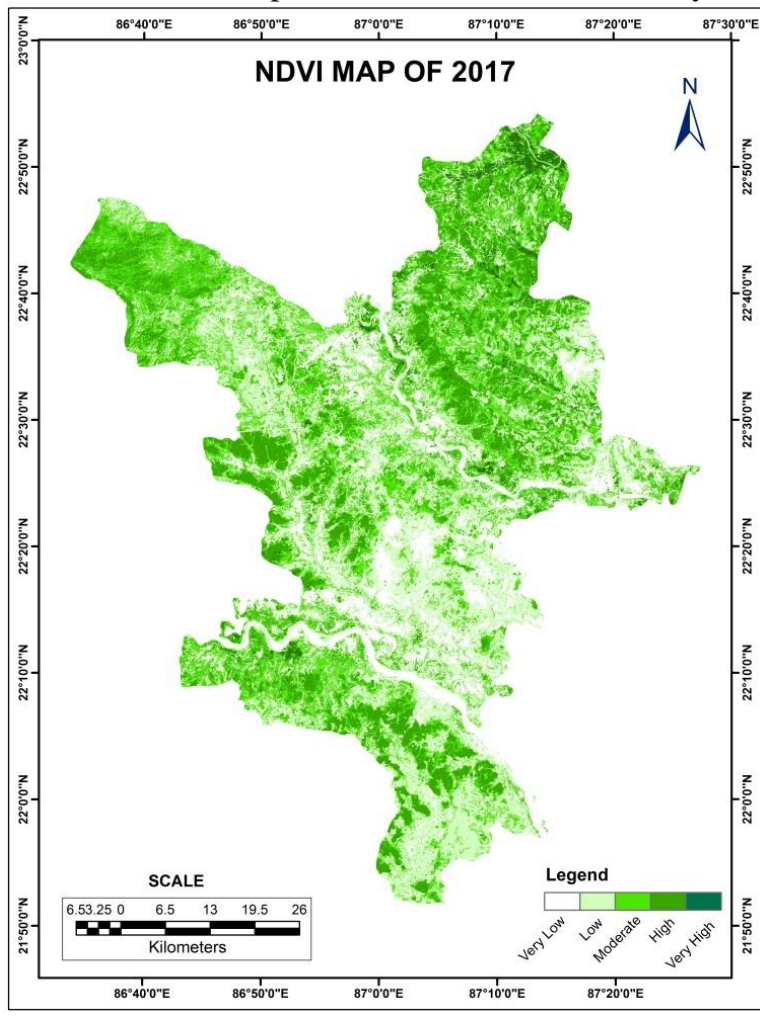

Figure 3 NDVI Map of 2017

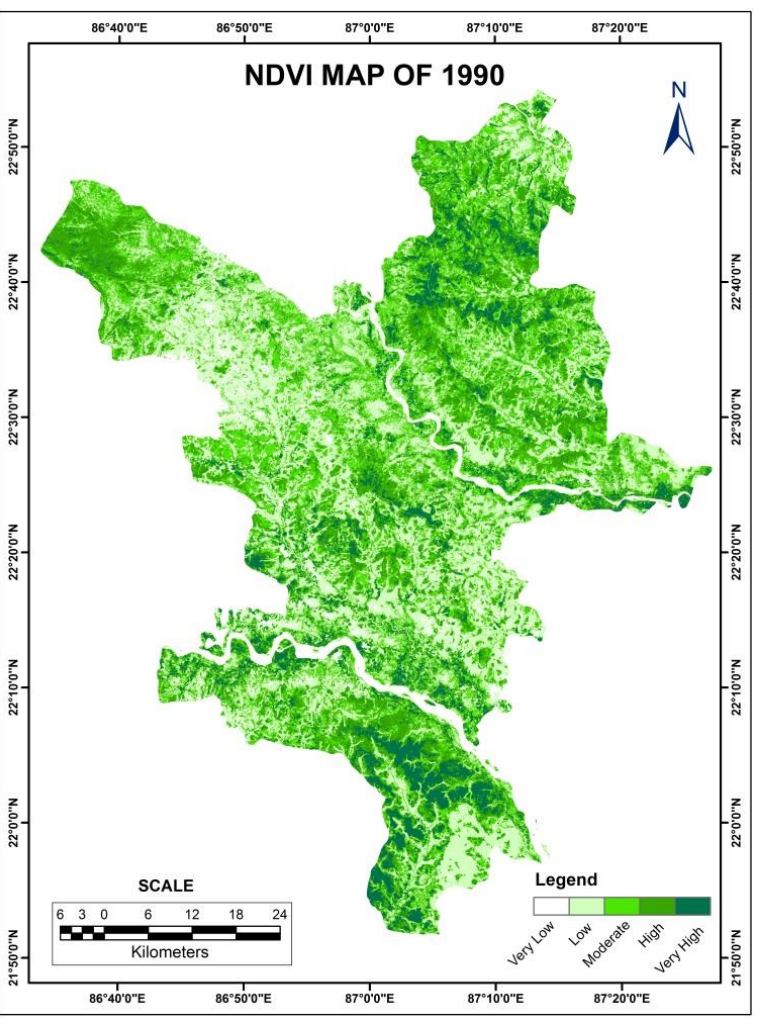

Figure 4 NDVI Map of 1990

\subsection{Environmental Impact of Change}

The present and past conditions, the positive and negative trends experienced by the people of the research study area is traditionally primary knowledge of information and the secondary information indicates that the impact on the environment decreasing in descending order of magnitude of rainfall, wildlife in forest area, yields and ground water and surface water.

\section{MANAGEMENT PLAN}

The growth of settlements and the others human activities like mining activities, agricultural construction are also considered to make any management plan in any forest region. The major source of income of the study area is orchard generating. The assessment of forest damages, suppression and management of bush fire, succession, regeneration, new plantation is needed.

\section{RESULT AND DISCUSSION}

The Normalized Difference Vegetation Index maps reflect the changes of the forest coverage area during the period of 1990 and 2017. The analysis (Table 1) shows that the forest area of the study area has witnessed maximum change of density of the forest which is being reduced after heavy biotic influence. In the study area the habitation has mostly been expended a very short time periods. Thus, the forest area also been converted into agriculture land which is extent to exceeding the other forest types. The remote sensing and GIS technologies helps to find out the monitoring of forest cover change as well as settlement and agriculture land of the study area. Increasing population, their habitation and the economic condition for earning money those are find out for the major causes of forest degradation and negative impact on the surrounding area. The present and past conditions, the negative and the positives trends are experienced by the local people of the study area, traditionally primary knowledge of information and the secondary information indicates that the impact on the environment decreasing in descending order of magnitude of rainfall, wildlife in forest area, yields and ground water and surface water. 


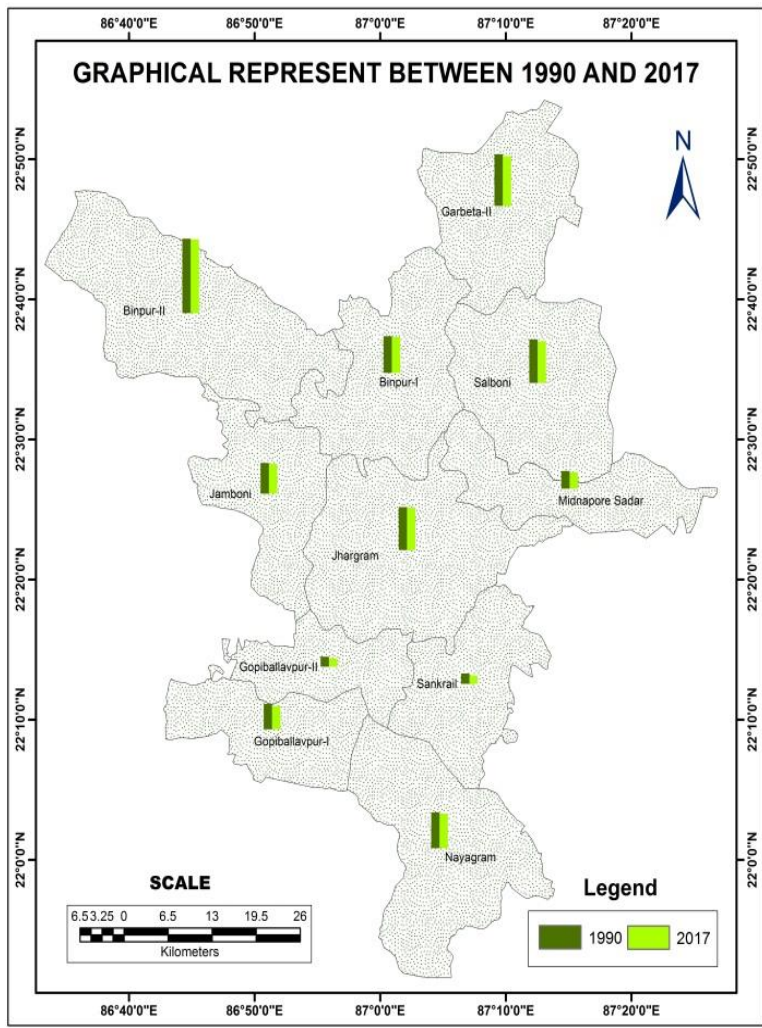

Figure 5 Graphical presentations between two years

In this present study the vegetation condition between the two periods 1990 to 2007 are graphically represented in figure 5 and also showing the amount of forest degradation in figure 6. The particular changed portion of forest cover over the two time periods of the study area is delineated, shown in figure7. The block wise forest cover areas in $\mathrm{Sq} \mathrm{km}$. over the two period's time $1990 \& 2007$ are showing in table 1 . The final valedictory result shows that between the two time periods of 27 years duration the vegetation covers has been highly decreased. The changed forest cover area difference was measured by overlay analysis and the output NDVI modelling data shows that the forest area as well as vegetation cover has been highly depleted in last 27 years.

\section{CONCLUSION}

The remote sensing data are used for analyzing and detecting the area of forest cover change in the study area. For detecting the changes in forest area, modelling techniques have been used to propagate a proper step for managing the land cover area,

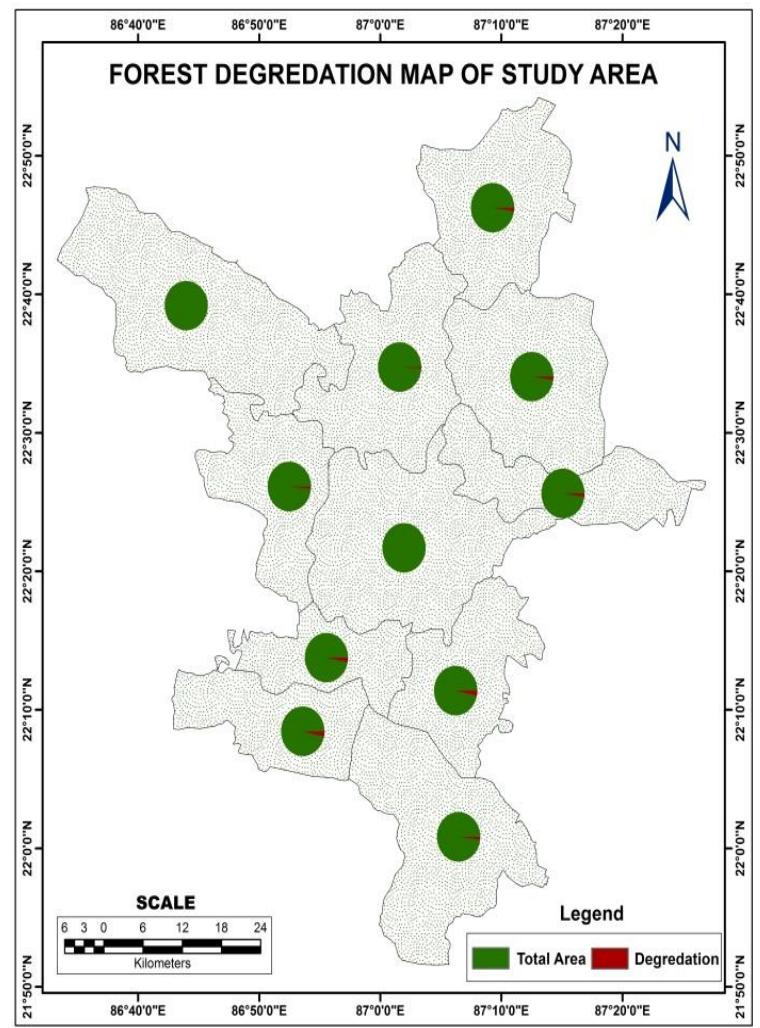

Figure 6 map of forest degradation

planning for conserving effective biodiversity, afforestation and betterment for local people and their surrounding environment. The overlay analysis and NDVI modelling has been successfully applied in remote sensing and GIS environment to identifying the vegetation conditions in the study area time to time. With the help of NDVI images, calculated between a long-term average NDVI in the year of 1990 and 2017, the spatial distribution of vegetation anomalies could be detected and vulnerable areas highlighted. The change detection techniques also applied for extraction changing forest cover area. It also clearly shows that the total forest area is continuously degrading and transforming into various land use categories. The remarkable decreased forest area is $81.37 \mathrm{sq}$. km. within the periods of 27 years between 1990 and 2017. So, systematic and sustainable forest management plan should be taken in particular forest region to protect the trees as well as forest products and others benefits. Governmental policies should be implemented for controlling the damage to the forest caused by natural or manmade. 
International Journal of Research in Advent Technology, Vol.7, No.5, May 2019

E-ISSN: 2321-9637

Available online at www.ijrat.org

\begin{tabular}{|c|c|c|c|c|c|}
\hline \multicolumn{6}{|c|}{ Jangalmahal Area } \\
\hline Districts & Block Name & $\begin{array}{c}\text { Total Area } \\
(\mathrm{Sq} . \mathrm{km})\end{array}$ & \begin{tabular}{|c|} 
Forest Area \\
$(\mathrm{Sq} . \mathrm{km})$ \\
1990 \\
\end{tabular} & \begin{tabular}{|c|} 
Forest Area \\
$(\mathrm{Sq} . \mathrm{km})$ \\
2017
\end{tabular} & $\begin{array}{c}\text { Block wise } \\
\text { Change } \\
(\mathrm{Sq} . \mathrm{km})\end{array}$ \\
\hline \multirow{8}{*}{ Jhargram } & Jhargram & 549.919 & 218.377 & 212.501 & 5.876 \\
\hline & Binpur-I & 411.723 & 185.883 & 181.522 & 4.361 \\
\hline & Binpur-II & 594.347 & 377.298 & 374.056 & 3.242 \\
\hline & Sankrail & 299.308 & 53.269 & 42.749 & 10.52 \\
\hline & Jamboni & 291.688 & 156.326 & 151.579 & 4.747 \\
\hline & Nayagram & 484.233 & 181.788 & 172.739 & 9.049 \\
\hline & Gopiballavpur-I & 265.078 & 127.822 & 118.148 & 9.664 \\
\hline & Gopiballavpur-II & 205.28 & 51.278 & 43.079 & 8.199 \\
\hline \multirow{3}{*}{$\begin{array}{c}\text { Paschim } \\
\text { Midnapore }\end{array}$} & Medinipur Sadar & 270.212 & 89.099 & 82.035 & 7.064 \\
\hline & Garbeta-II & 375.51 & 261.306 & 252.35 & 8.956 \\
\hline & Salboni & 439.901 & 220.579 & 210.884 & 9.695 \\
\hline & Total & 4187.199 & 1922.98 & 1841.64 & 81.37 \\
\hline
\end{tabular}

Table 1 Block wise forest area (1990 \& 2017)

\section{Acknowledgements:}

Authors would like to thank to the dept. of Remote sensing and GIS Vidyasagar University, West Bengal. Authors are also thankful to the Government of India for encouraging and support to research work.

\section{REFERENCE:}

[1] Anonymous: National forest policy. National commission on agriculture, ministry of agriculture and cooperation, New Delhi (1976).

[2] Green, K, Kempka, D and Lackey, L. 1994. Using remote sensing to detect and monitor land-cover and land-use change. Photogrammetric Engineering and Remote Sensing, 60: 331-337. [Web of Science ®], [Google Scholar].

[3] Hoffer, R. M., (1986) Digital analysis techniques for forestry applications, Remote Sensing Reviews, Vol. 2, pp 61-110.

[4] Pilon P., Howarth P. (1988), An enhanced classification approach to change detection in semi-arid environments, Photogrammetric Engineering and Remote Sensing, 54, pp.17091716, 1988.

[5] Sakthivel R., Manivel M., Jawaharaj N., Pugalanthi V., Ravichandran N. and Vijay D. Anand (2010), Remote sensing and GIS based forest cover change detection study in Kalrayan hills, Tamil Nadu, Journal of Environmental Biology, pp. 737-747.

[6] Rouse, J.W., R.H. Haas, J.A. Schell, and D.W. Deering, (1974) Monitoring vegetation systems in the Great Plains with ERTS, In: S.C. Freden, E.P. Mercanti, and M. Becker (eds) Third Earth

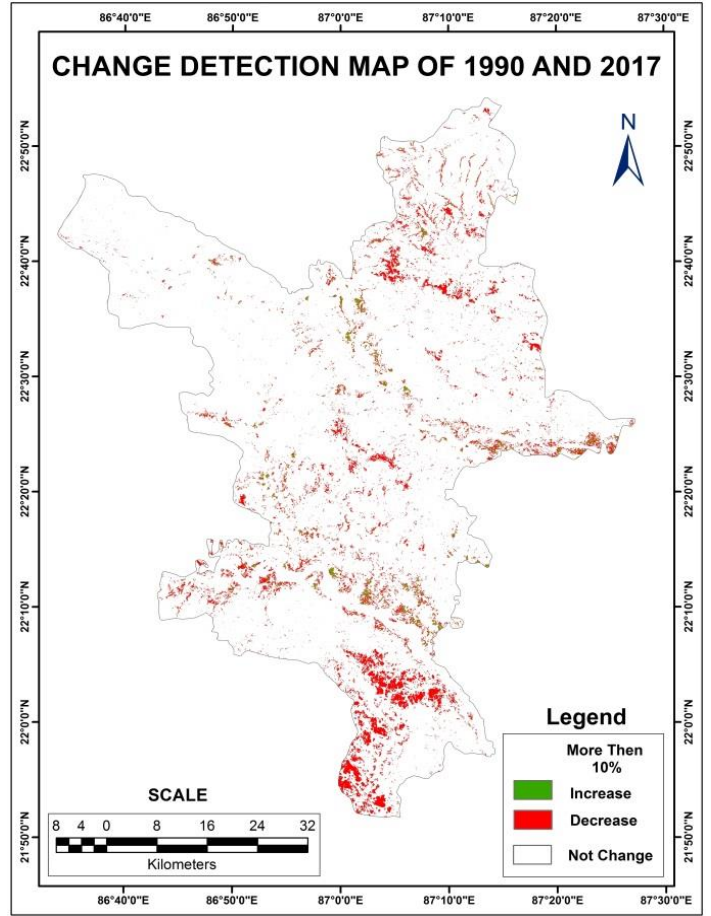

Figure 7 Map of change area

Resources Technology Satellite-1 Syposium. Volume I: Technical Presentations, NASA SP351, NASA, Washington, D.C., pp 309-317.

[7] Verburg, P.H., Overmars, K.P., Huigen, M.G.A., de Groot, W.T. and Veldkamp, A. (2006) Analysis of the Effects of Land Use Change on Protected Areas in the Philippines. Applied Geography, 26, pp. 153-173.

[8] Sader, S. A., Joyce , A. T., Waide, R. B., Lawrence, W.T. (1985) Monitoring tropical forests from satellite and aircraft platforms: Some limitations and new approaches, In proc. PECORA 10 - Remote sensing in forest and range resource management, Colorado State University, Fort Collins Co., USA.

[9] Wilson, E. H and Sader, S. A. (2002) Detection of forest harvest type using multiple dates of Landsat TM imagery. Remote Sensing of Environment, 80: 385-396. [CrossRef], [Web of Science ${ }^{\circledR}$ ], [CSA]. 